\title{
CAPITAL SOCIAL E EMPREENDEDORISMO: A INFLUÊNCIA DAS DIMENSÕES OFFLINE E ONLINE AOS EMPREENDEDORES INICIAIS
}

Tatiane Andreza De Souza Silva ${ }^{1}$

Victor Corrêa ${ }^{1}$

Glaucia Vale ${ }^{2}$

Ernesto Michelangelo Giglio ${ }^{1}$

\footnotetext{
${ }^{1}$ Universidade Paulista

${ }^{2}$ Pontifícia Universidade Católica de Minas Gerais - PUC Minas
} 


\section{CAPITAL SOCIAL E EMPREENDEDORISMO: A INFLUÊNCIA DAS DIMENSÕES OFFLINE E ONLINE AOS EMPREENDEDORES INICIAIS}

Resumo: Insere-se na literatura sobre Capital Social a noção de que ele seria de natureza "offline", associado aos relacionamentos essencialmente presenciais. Mas, poderia o ambiente "online", expresso nas interações nas mídias sociais - altamente emergente e ainda pouco explorado -, fornecer capital social aos empreendedores? Este artigo, uma contribuição aos estudos da área, insere-se no contexto desta reflexão. Busca investigar se e como os capitais sociais offline e online influenciam os empreendedores. Faz isto através do estudo qualitativo de três empreendedores de pequeno porte e em "Estágio Inicial", com até 42 meses de existência. Dados de campo sugerem: i.) a importância combinada dos capitais sociais offline e online; ii.) a atuação diferenciada entre ambos os tipos, e; iii.) a existência de recursividade entre recursos derivados das duas esferas (offline e online). Ao concluir isto, este artigo projeta luzes para novas reflexões, e suscita a necessidade de mais estudos teórico-empíricos ainda hoje intocados.

Palavras-chave: Mídias Sociais. Capital Social. Empreendedorismo. Sites de Redes Sociais.

\section{$1 \quad$ Introdução}

O estudo da "influência do capital social sobre o empreendedorismo tem crescido ao longo dos últimos anos" (Neira, Calvo, Fernández, \& Portela, 2017, p. 668). Salientam Smith, Smith and Shaw (2017, p. 19), por exemplo, como "substancial corpo de pesquisa [tem] indicado o capital social [como] fundamental ao sucesso dos empreendimentos" (Smith, Smith, \& Shaw, 2017, p. 19); como a "teoria do capital social tem feito significativas incursões" no estudo sobre o tema (Afandi, Kermani, \& Mammadov, 2017, p. 686). Considerado ativo fundamental aos empreendedores (Pedrini, Bramanti, \& Cannatelli, 2016), um atributo essencial ao desenvolvimento de seus empreendimentos (Afandi, Kermani, \& Mammadov, 2017), o capital social, ou, dito de outra maneira, "os recursos que os empreendedores podem acessar através de suas redes pessoais", manifesta-se na possibilidade de os empreendedores identificarem oportunidades" (Stam, Arzlanian, \& Elfring, 2014, p. 153), ganhar credibilidade, acessar informações, obter acesso a escassos recursos financeiros, intelectuais (Vixathep, 2017, p. 37), capacidades comerciais e de negócios (Hernández-Carrión, Camarero-Izquierdo, \& Gutiérrez-Cillán, 2017), entre outros.

É possível observar na literatura sobre capital social a manifestação de diferentes abordagens e níveis de análise (Afandi, Kermani and Mammadov, 2017; Kim \& Kang, 2014). Argumenta Kaasa (2009, p. 4) como "capital social tem muitas dimensões que precisam ser levadas em consideração". Inserir-se-iam, por exemplo, o capital social comunitário (Naseri, 2017), localizado (Giudici, Guerini, \& Rossi-Lamastra, 2017), coletivo (Hernández-Carrión, Camarero-Izquierdo, \& Gutiérrez-Cillán, 2017), organizacional (Luu, 2017), entre outros. Dois deles, de natureza estrutural (Han, 2018) e "inter-relacionados" entre si (Naseri, 2017), "têm ganhado destaque na literatura sobre empreendedorismo" (Smith, Smith, \& Shaw, 2017, p. 20): 
o capital social derivado do fechamento (Bonding) e o do buraco estrutural (Bridging) (Birendra, Morais, Seekamp, Smith, \& Peterson, 2015; Hernández-Carrión, CamareroIzquierdo, \& Gutiérrez-Cillán, 2017; Naseri, 2017; Wahid \& Indarti, 2013). Consideradas "as duas dimensões mais importantes do capital social" (Ryu, 2017, p. 4), ou, segundo Han (2018, $\mathrm{s} / \mathrm{p}$ ), aquelas que "receberam mais atenção de pesquisa" ao longo dos últimos anos, elas têm sido em grande medida a "base para os trabalhos sobre" o tema (Burt, 2000, p. 350).

Enquanto a perspectiva do fechamento se associa às reflexões de Granovetter (1973) sobre laços fortes, a dos Buracos Estruturais, por sua vez, encontra ressonância nas reflexões deste autor sobre a força dos laços fracos (Granovetter, 1973). De fato, salienta Bucholtz (2019, p. 12) como "capital social de ligação (Bonding) está relacionado aos contatos derivados dos laços fortes", enquanto "capital social de intermediação (Bridging) é comumente associado aos relacionamentos de laços fracos" (Bucholtz, 2019, p. 12). Em outras palavras, bonding implica homogeneidade de conexões, bridging, por sua vez, heterogeneidade entre elas (Mahmood, Zakar, \& Zakar, 2018; Naseri, 2017). Uma prática comum na literatura é se "referir ao capital social em termos das características dos relacionamentos através dos quais os recursos são derivados, mas não os recursos em si” (Hernández-Carrión et al., 2017, p. 62). Para efeito deste trabalho, compreender-se-á capital social como as características das redes (Hernández-Carrión et al., 2017), e, também, como os "recursos localizados nos laços internos (associados ao capital social do fechamento) e externos (associados com a intermediação) de um ator" (HernándezCarrión, Camarero-Izquierdo, \& Gutiérrez-Cillán, 2017, p. 63); isto é, os "recursos que podem ser acessados ou mobilizados através do laços nas redes" (Bucholtz, 2019, p. 3).

É possível observar, na essência da literatura sobre capital social associada ao empreendedorismo, a manifestação de algumas concepções fundamentais. A primeira, já salientada, é de que capital social seria importante aos empreendedores (Afandi, Kermani, \& Mammadov, 2017; Bastié, Cussy, \& Nadant, 2016; Pedrini, Bramanti, \& Cannatelli, 2016; Vixathep, 2017). A segunda de que tanto "fechamento" (bonding) quanto "conexão" (bridging) "desempenham papel importante no [...] acesso a diferentes tipos de recursos" (Bucholtz, 2019, p. 3). A terceira, por sua vez, é aqui de interesse particular. Insere-se na literatura sobre capital social a noção, implícita e vigente, de que ele seria de natureza "offline", associado ao que Williams (2006, p. 593) denominou de "vida real". Em outras palavras, o capital social seria os recursos obtiveis pelos empreendedores através de suas interações presenciais, fortes ou fracas (Williams, 2006). Contudo, outro tipo de capital social, altamente emergente, vem ganhando particular destaque nas reflexões sobre o tema: o de natureza "online", expresso nos recursos que os empreendedores obtêm através das mídias sociais, da internet, isto é, do ambiente digital de maneira geral (Bucholtz, 2019; Naseri, 2017; Wahid, \& Indarti, 2013). Evidências episodiais, ainda pouco exploradas pela literatura, sugerem a noção de que os "empreendedores usam os sites de redes sociais de maneira diferente das redes offline para acumular capital social" (Smith, Smith, \& Shaw, 2017, p. 18).

Este artigo, uma contribuição aos estudos da área, insere-se justamente aí. Sob perspectiva teórica, busca investigar se e como os capitais sociais offline e online influenciam os empreendedores, analisando os recursos derivados e a dinâmica entre eles. Faz-se isto, sob abordagem empírica, através do estudo qualitativo de tipo particular de empreendedor, de pequeno porte e em "Estágio Inicial", isto é, com até 42 meses de existência (GEM, 2018). Tal esforço não se demonstra em vão. De fato, cerca de 25 milhões de pessoas no Brasil, 
aproximadamente $46 \%$ do total de empreendedores do país, são empreendedores em estágio inicial (GEM, 2018). Somente em 2018, mais de 2,5 milhões de novas empresas foram criadas, número $15 \%$ superior à quantidade registrada no ano anterior (https://www.serasaexperian.com.br/). Na esteira destes dados positivos se insere, contudo, cenário ainda hoje desolador. Uma a cada quatro empresas encerra suas atividades antes de completar dois anos no mercado (Sebrae). Note, aí, a relevância de se compreender distintos fatores, dentre os quais se inserem os relacionais, aqui de interesse particular, capazes de influenciar a trajetória de empreendimentos em estágio inicial. Com efeito, salientam Fósic, Kristic e Trusic (2017, p. 339) como "a primeira etapa do início de um negócio é o estágio mais desafiador de uma carreira empreendedora".

Este artigo se insere em meio a distintas lacunas de pesquisas. A primeira se relaciona ao próprio estudo do capital social no contexto digital. Defende Naseri (2017, p. 13) como os "cientistas sociais precisam lidar com novos conceitos e implicações do capital social na era dos sites de redes sociais". Apesar disso, argumentam Smith, Smith and Shaw (2017, p. 18), "poucos estudos têm considerado o capital social empreendedor no contexto online". Mesmo entre os que investigam o capital social online, ainda são "poucos [...] os que têm tentado" (Bucholtz, 2019, p. 4), a exemplo do aqui também proposto, reexaminar, no ambiente digital, a influência de ambas as dimensões do capital social (bonding e bridging), por um lado, e "a justaposição entre o capital social do fechamento e do buraco estrutural", por outro (Bucholtz, 2019 , p. 4). Salienta Naseri (2017, p. 15), por exemplo, como "poucas pesquisas têm examinado o relacionamento entre a internet e o capital social de ligação". Já Bucholtz $(2019$, p. 4) enfatiza como o conhecimento sobre as "características do capital social de ligação (bonding) e intermediação (bridging) em ambiente online é [ainda hoje] limitado, digno de investigações adicionais".

Outra lacuna se relacionaria à própria associação entre os capitais sociais offline e online. Evidências sugerem que as pessoas "constroem, mantêm e usam as redes sociais [no ambiente online de maneira] substancialmente diferente das interações face-a-face" (Smith, Smith, \& Shaw, 2017, p. 22). De fato, no contexto digital, o "tempo e o espaço são comprimidos, a velocidade de interação é acelerada e as pessoas se encontram cada vez mais acessíveis" (Smith, Smith, \& Shaw, 2017, p. 22). Apesar disso, complementam os autores, ainda "não está claro até que ponto ou como o capital social dos empreendedores se manifesta" em ambos os ambientes sociais (Smith, Smith, \& Shaw, 2017, p. 18). Mais que isso, não está claro se o capital social do ambiente offline, usualmente desenvolvido em longos períodos de tempo, é de algum modo "transferível aos relacionamentos online dos empreendedores" (Smith, Smith, \& Shaw, 2017, p. 21).

Finalmente, a terceira é empírica. Associa-se a ainda hoje carência de estudos que buscaram, à luz da literatura sobre capital social, em geral, e sobre capital social offline e online, em particular, investigar fatores relacionais que impactam a trajetória e o desenvolvimento de empreendimentos iniciais no país. De fato, em busca por títulos (capital social and inici* | capital social and criação de empresa*) de artigos publicados no Brasil nos últimos 5 anos e disponíveis no Portal de Periódicos Capes, não foram encontrados trabalhos que buscaram compreender a importância do capital social offline e online ao desenvolvimento de empreendimentos com até 42 meses. Estre trabalho se insere aí, procurando preencher parte destas diferentes lacunas de pesquisa. 
O capital social pode ser avaliado como um dos "mais influentes conceitos da ciência social ao longo das últimas duas décadas" (Lewis \& Chamlee-Wright, 2008, p. 107). Considerado um recurso produtivo tão importante quanto outros tipos de capital, tais como financeiro e humano, o capital social têm sido objeto de estudos por pesquisadores de vários campos de conhecimento (Ryu, 2017; Stam, Arzlanian, \& Elfring, 2014). Inserem-se, aí, por exemplo, saúde pública (Levesque \& Quesnel-Vallée, 2019), economia (Ahmad \& Khan, 2019), sociologia (Gayen; Raeside; Mcquaid, 2019), entre outros. Um deles, aqui de interesse particular, relaciona-se à temática do empreendedorismo. Salientam Afandi, Kermani and Mammadov (2017, p. 687) como a "teoria do capital social tem feito incursões significativas nas pesquisas sobre empreendedorismo"; como "o capital social é um elemento chave para o desenvolvimento do comportamento empreendedor". Apesar disto, isto é, a despeito da relevância do capital social ao empreendedorismo, ainda prevalece sobre a literatura da área a ausência de núcleo teórico consolidado (Hoang \& Antoncic, 2003; Smith, Smith, \& Shaw, 2017; Williams, Huggins, \& Thompson, 2017). Salientam Smith, Smith and Shaw (2017), por exemplo, como a área tem sofrido com falta de precisão e consistência; como seria importante "aprofundar-se na miríade de definições que [são] empregadas para identificar e explicar os fenômenos que podem ser considerados como constituindo capital social" (Williams, Huggins, \& Thompson, 2017, p. 2).

Parte desta imprecisão conceitual se relaciona às diferentes dimensões e níveis de análise associados ao conceito (Fukugawa, 2018). Com efeito, enquanto alguns autores, fundamentados em uma perspectiva estrutural, definem-no como resultado do posicionamento do empreendedor em dada rede Fukugawa, 2018; Han, 2018; Yoon, Yun, Lee, \& Phillips, 2015), outros, influenciados por abordagem relacional, por sua vez, consideram-no como resultado da "natureza e da qualidade das interações" entre indivíduos (Hmieleski, Carr, \& Baron, 2015; Stam, Arzlanian, \& Elfring, 2014, p. 154). Hmieleski, Carr and Baron (2015, p. 295), "seguindo Granovetter", por exemplo, "distinguem capital social como resultante dos laços fracos e laços fortes". Contudo, diferentes autores vêm salientando a possibilidade de integrar ambos os níveis de análise (Fukugawa, 2018; Nahapiet \& Ghoshal, 1998). Ao comentarem sobre a relação entre diferentes dimensões do capital social, Nahapiet e Ghoshal (1998) afirmaram como nem todas são mutuamente reforçadas, mas a dimensão estrutural do capital social influencia o desenvolvimento da relacional; isto é, podem ser consideradas complementares em si. Neste sentido, para efeito deste trabalho, compreender-se-á capital social como as características das redes (estrutural) (Hernández-Carrión et al., 2017), e, também, como os "recursos localizados nos laços internos (associados ao capital social do fechamento) e externos (associados com a intermediação) de um ator" (relacional) (Hernández-Carrión, Camarero-Izquierdo, \& Gutiérrez-Cillán, 2017, p. 63).

Duas das "mais importantes [dimensões] do capital social" (Ryu, 2017, p. 4), aquelas que "receberam mais atenção de pesquisa" ao longo dos últimos anos" (Han, 2018, s/p), serão aqui enfatizadas: a derivada do fechamento (Bonding) e a do buraco estrutural (Bridging) (Birendra et al., 2018; Hernández-Carrión, Camarero-Izquierdo, \& Gutiérrez-Cillán, 2017; Naseri, 2017; Wahid, \& Indarti, 2013). Embora a distinção entre fechamento (bonding) e 
buracos estruturais (bridging) remontem a autores como Putnam (2000), as reflexões sobre o tema vão encontrar em Coleman (1988) e Burt (2009) dois de seus principais expoentes. Enquanto Coleman $(1988,1990)$ associa capital social aos recursos imersos em redes coesas, Burt (2009), por sua vez, interpreta-o como sendo resultado da intermediação entre redes densas e desconexas entre si.

Surgida no final da década de 1980, a primeira abordagem é denominada de Fechamento ou Oclusão (Coleman, 1988, 1990). A argumentação principal é a de que redes fechadas proporcionam importantes vantagens às pessoas (Coleman, 1988, 1990). Três delas são destacadas pelo autor. A primeira relaciona-se com as obrigações e a confiabilidade dos agrupamentos sociais. Segundo Coleman (1988, p. 103), "aqueles indivíduos que se encontram em estruturas sociais com altos níveis de obrigações pendentes possuem mais capital social sobre o qual podem se basear". A segunda vantagem relaciona-se à possibilidade de se aplicar sanções. Este atributo contribui para tornar menos arriscado às pessoas confiar umas nas outras, e para estimular nos indivíduos o desenvolvimento de comportamento mutuamente cooperativo (Coleman, 1988). Finalmente, o terceiro benefício associa-se à facilidade de acesso aos recursos (capital social) unicamente disponíveis nos agrupamentos fechados. "Um meio pelo qual as informações podem ser adquiridas é [através] das relações sociais [coesas] que são mantidas para outros objetivos" (Coleman, 1988, p. 104). Note como o conceito de capital social de James Coleman (1988) se baseia no argumento de que é a oclusão das redes - derivada de estruturas formadas por laços fortes - que proporciona aos indivíduos maior acesso a importantes benefícios.

Outra vertente de raciocínio, a de Ronald Burt (2004, 2009), no entanto, projeta luzes para distinta perspectiva do capital social, em que sua origem, embora igualmente relacionada à estrutura de relações entre atores, derivaria das oportunidades de intermediação entre diferentes redes $(2004,2009)$. A proposição central de Burt $(2004,2009)$ é a de que atores que possuem laços fracos em dessemelhantes agrupamentos densos e separados entre si encontramse em estratégica posição de vantagem em relação aos demais (Burt, 2009). Na medida em que constituem única rota possível através da qual distintos e exclusivos recursos podem fluir de uma rede a outra, eles podem explorar antecipadamente os benefícios do "buraco estrutural" (Burt, 2004, 2009), termo cunhado para ilustrar situações nas quais lacunas separam contatos não redundantes imersos em grupos dispostos de recursos mutuamente adicionais (Burt, 2004, 2008, 2009).

Insere-se, na essência da literatura sobre capital social, a noção, implícita e vigente, de que ele seria de natureza "offline", associado ao que Williams (2006, p. 593) denominou de "vida real". Isto é, relacionar-se-ia aos recursos derivados dos relacionais presenciais (Williams, 2006). Contudo, outro tipo de capital social, ainda inexplorado pela literatura da Administração no Brasil, vem ganhando relevância no desenvolvimento de empreendimentos produtivos: o de natureza online, aqui compreendido como os recursos obtidos pelos empreendedores através dos relacionamentos nas mídias sociais ou sites de redes sociais (SRS) (Bucholtz, 2019; Naseri, 2017; Wahid, \& Indarti, 2013). Tal reflexão não é em vão. Salientam Smith, Smith and Shaw (2017, p, 21) como "diferenças nos contextos online e offline [podem] afetar os tipos de oportunidades [e de recursos] nos quais os empreendedores" têm acesso, "bem como a extensão na qual o capital social é desenvolvido, acessado e utilizado" (Smith, Smith, \& Shaw, 2017, p. 21). De fato, segundo os autores, "as pessoas constroem, mantêm e usam as 
redes sociais [no ambiente online de maneira] substancialmente diferente das interações facea-face" (Smith, Smith, \& Shaw, 2017, p. 22).

Definidas como espaços que permitem aos usuários a criação de perfis públicos ou semipúblicos (Boyd \& Ellison, 2007), as mídias sociais podem ser de diferentes tipos, tais como websites colaborativos, blogs, microblogs, sites de redes sociais, mundos virtuais, sites de compartilhamentos, entre outros (Kaplan \& Haenlein, 2010). Conquanto possam ser utilizadas para diferentes fins, aos empreendedores, em particular, as mídias sociais aparentam apresentar características peculiares (Kaplan \& Haenlein, 2010; Smith, Smith, \& Shaw, 2017). Salientam Smith, Smith and Shaw (2017, p. 22) como "empreendedores têm objetivos diferentes para o uso dos sites de redes sociais". A busca pelo capital social online é mais arriscado quando se comparado aos demais indivíduos. A "importância do capital social para o sucesso do empreendimento [depende] se o capital social [é] gerenciado de forma eficaz" (Smith, Smith, \& Shaw, 2017, p. 22). No geral, as mídias sociais possuem algumas características que podem impactar a forma e o tipo de capital social - fechamento ou buraco estrutural - no qual o empreendedor tem acesso no ambiente digital. Quatro delas são atualmente destacadas pela literatura (Kane, Alavi, Labianca, \& Borgatti, 2014; Smith, Smith, \& Shaw, 2017; Wahid \& Indarti, 2013). São elas: I) perfis de usuário digital; II) pesquisas digitais; III) relações digitais e IV.) transparência de rede.

Os perfis de usuário digital exibem dados fornecidos pelos usuários. "Esse recurso permite que os empreendedores criem, editem, compartilhem e dupliquem informações que forneçam insights para outras pessoas" (Smith, Smith, \& Shaw, 2017, p. 22). De fato, "Os perfis frequentemente incluem [...] informações sobre sua identidade, valores e caráter, entre outros atributos" (Smith, Smith, \& Shaw, 2017, p. 22). Já a busca digital permite que os empreendedores "digitalizem, visualizem, revisem ou extraiam conteúdo da rede" (Smith, Smith, \& Shaw, 2017, p. 22). As relações digitais, por sua vez, permitem aos "empreendedores interagirem de maneira fácil e econômica com os outros para desenvolver laços fracos e fortes" (Smith, Smith, \& Shaw, 2017, p. 22). Finalmente, a transparência de rede é um recurso dos sites de redes sociais que mostra a rede de um usuário em sua totalidade. Proporciona "aos empreendedores e aos seus contatos a oportunidade para visualizar conexões, identificar conexões ausentes e fazer inferências sobre associação ou dissociação" (Smith, Smith, \& Shaw, 2017, p. 22). Tais características são, por sua vez, desdobradas em recursos específicos (affordances), isto é, em atributos que permitem aos empreendedores o acesso a dado benefício relacionado, no ambiente digital, ao fechamento e/ou ao buraco estrutural (Smith, Smith, \& Shaw, 2017). A literatura da área identificou 16 até o momento. O Quadro 1, a seguir, apresenta-os em resumo, e associa-os ao mesmo tempo às características das redes sociais, por um lado, e aos tipos de capital social (fechamento e buracos estruturais), por outro.

Quadro 1: Características dos sites de redes sociais, seus recursos específicos e sua associação com capital social de fechamento e de buraco estrutural.

\begin{tabular}{|c|c|c|}
\hline $\begin{array}{l}\text { Características dos Sites de Redes } \\
\text { Sociais }\end{array}$ & Capital Social de Ligação & $\begin{array}{l}\text { Capital Social de } \\
\text { Buraco Estrutural }\end{array}$ \\
\hline \multirow{3}{*}{ Perfis de usuários digitais } & Compartilhamento & Sinalização \\
\hline & Sinalização & Replicabilidade \\
\hline & Visibilidade (viewability) & - \\
\hline
\end{tabular}




\begin{tabular}{|l|l|l|}
\hline \multirow{3}{*}{ Pesquisa Digital } & Editabilidade & - \\
\hline \multirow{3}{*}{ Relações Digitais } & Persistencia & Pesquisabilidade \\
\cline { 2 - 3 } & Revisibilidade & Recuperabilidade \\
\cline { 2 - 3 } & Assincronia & Assincronia \\
\hline \multirow{3}{*}{ Transparência de Rede } & Interatividade Social & Interatividade Social \\
\cline { 2 - 3 } & Escalabilidade & Escalabilidade \\
\cline { 2 - 3 } & Interoperabilidade & Interoperabilidade \\
\hline & Visibilidade & Assibilidade \\
\cline { 2 - 3 } & - & Transção \\
\cline { 2 - 3 } & - & \\
\hline
\end{tabular}

Fonte: adaptado de Smith, Smith, \& Shaw (2017)

O "compartilhamento", como o próprio nome sugere, é a habilidade de compartilhar o conteúdo do perfil digital com diversos outros indivíduos do ambiente online. Considerado um recurso dos "perfis de usuários digitais", ele permitiria aos empreendedores capital social de fechamento (Smith, Smith, \& Shaw, 2017). Já a "sinalização" seria capaz de fornecer ambos os tipos de capital social. Indicaria a habilidade de transmitir informações intencionais e não intencionais dos perfis dos usuários (Donath, 2007). Outros dois recursos associados que forneceriam capital social de fechamento seriam a "visibilidade" e a "editabilidade". Enquanto o primeiro se refere à capacidade de visualizar conteúdos de perfis restritos, o segundo, por sua vez, relacionar-se-ia à habilidade de reconsiderar ou recriar conteúdos dos perfis antes de compartilhá-los. Ainda em relação aos "perfis de usuários", a "replicabilidade", que se refere à habilidade para duplicar ou modificar o conteúdo do perfil, permitiria capital social de buracos estruturais (Smith, Smith, \& Shaw, 2017).

Em relação à "pesquisa digital”, segunda característica das mídias digitais, seria possível observar cinco recursos específicos, sendo dois deles relacionados ao capital social de fechamento (Persistência e Revisibilidade), dois associados ao capital social de buraco estrutural (Pesquisabilidade e Recuperabilidade), e um, denominado "assincronia", que permitiria ambos os tipos de capital social. A "Persistência" se associa à possibilidade de ver informações arquivadas. Já a "Revisibilidade" associar-se-ia à possibilidade de avaliar e revisar a consistência das postagens ao longo do tempo. Por sua vez, "Pesquisabilidade" se relaciona à capacidade de pesquisar com eficiência todo tipo de conteúdo dos sites de redes sociais, enquanto "Recuperabilidade" é a habilidade de vascular as redes para capturar informações específicas. Finalmente, "assincronia" se associa à habilidade para superar limitações temporais e extrair conteúdos de laços unidirecionais" (Smith, Smith, \& Shaw, 2017).

A terceira característica das redes sociais é as "relações digitais". Elas permitiram três recursos específicos, todos associados aos dois tipos de capital social (Interatividade Social, Escalabilidade e Interoperabilidade). O primeiro seria a habilidade de se conectar com eficiência às outras pessoas das redes. $\mathrm{O}$ segundo, por sua vez, seria a capacidade de, no ambiente digital, enviar e receber informações em grande escala. Já o terceiro seria a possibilidade de compartilhar conteúdos através de múltiplas e distintas plataformas digitais. Finalmente, a quarta característica das redes (Transparência das Redes) permitiria aos empreendedores três outros recursos adicionais, sendo um associado aos dois tipos de capital social (visibilidade), e outros dois (Associação e Transversabilidade) capazes de permitir, somente, recursos derivados dos buracos estruturais. A "visibilidade" seria a habilidade de 
tornar todas as conexões de redes visíveis. "Associação", por sua vez, seria a capacidade de saber que existe uma conexão de rede. Finalmente, "Transversabilidade" seria a habilidade para navegar para e através de sua própria rede e a de outros.

\section{Base Metodológica}

A estratégia de pesquisa empregada foi qualitativa, considerada adequada às investigações do capital social no ambiente online, em que medidas operacionais ainda não foram estabelecidas. De fato, salientam Smith, Smith and Shaw (2017, p. 32) como a "novidade dos sites de redes sociais", a ainda hoje "ausência de medidas estabelecidas de construtos-chave e o desafio de separar os comportamentos online e offline" fazem com que estratégias e métodos qualitativos sejam particularmente relevantes. Tal foi o caso do presente estudo, de natureza qualitativa. Segundo os autores, metodologias qualitativas, dentre as quais se inserem o Estudo de Caso, aqui empregado, "são particularmente adequadas para filtrar a complexidade do capital social" (Smith, Smith, \& Shaw, 2017, p. 32). Empregou-se o método de estudo de caso holístico e descritivo (Yin, 2015), considerado adequado às situações, a exemplo da aqui proposta, em que se busca investigar dado "fenômeno contemporâneo". Ele também é adequado às "ocasiões em que os limites entre o fenômeno e o contexto não são claramente evidentes (Yin, 2015, p. 17). Tal é o caso do presente estudo.

O caso é os pequenos empreendimentos em estágio inicial, isto é, com até 42 meses de existência (GEM, 2018). Os empreendedores responsáveis se constituíram Unidade Empírica de Análise ao mesmo tempo que de Observação (Yin, 2015). O tipo de estudo de caso foi múltiplo, cujas evidências são consideradas mais robustas (Yin, 2015). Salienta Yin (2015, p. 28) como "tentar usar até mesmo um projeto de 'dois casos' é um objetivo valioso comparado com a realização de um estudo de caso único". Para efeito deste trabalho, foram selecionados três casos: Pimentas Lucha Libre (Caso 1), Hortelar Servicos Ltda (Caso 2) e Afro Brasil Eventos e Turismo (Caso 3). A primeira é uma pequena indústria de indústria de fabricação de conservas caseiras, com produção de molho de pimentas, conservas e geleias, e faturamento médio bruto anual de 180 mil reais. A segunda presta serviços de arquitetura empresarial, criação e cuidados com hortas escolares e residenciais. Tem um faturamento médio anual de 100 mil reais. Finalmente, a terceira é uma agência de viagens com faturamento bruto anual aproximado de 40 mil reais.

A seleção dos casos se baseou em critérios teóricos, isto é, nos objetivos da investigação (Eisenhardt, Graebner, \& Sonenshein, 2016). Buscou-se analisar se e como os capitais sociais offline e online (Facebook, WhatsApp, sites, blogs, etc.) influenciam a trajetória inicial dos empreendedores (até 42 meses), analisando ao mesmo tempo os recursos derivados e a dinâmica entre eles. Para isto, a entrevista semiestruturada em profundidade foi empregada como técnica de coleta das evidências. Ela é considerada uma das mais importantes técnicas dos estudos de caso (Gaskell, 2002; Yin, 2015). As entrevistas buscaram a saturação teórica, obtida nas ocasiões em que as evidências se demonstravam confirmatórias, em que "os discursos não constituíam contribuições adicionais significativas às análises dos dados e às conclusões do estudo" (Paiva Junior, Leão, \& Mello, 2011, s/p). A estratégia analítica geral se fundamentou nas proposições teóricas, em que as evidências de campo foram contrastadas à literatura subjacente (Yin, 2015). Isto é, "a orientação teórica guiou a análise do estudo de caso" (Yin, 
2015, p. 141). O formato do relatório de estudo de caso foi fundamentado na análise entre os casos, em que as "informações dos casos individuais foram apresentadas ao longo" das reflexões, estas agrupadas teoricamente (Yin, 2015, p. 190).

\section{Descrição e Análise dos Dados}

É possível observar, à luz dos dados empíricos, a importância do capital social offline aos empreendedores iniciais. Dados de campo sugerem a importância destacada de ambos os tipos de capital social (fechamento e buracos estruturais) à busca pelo desenvolvimento de seus empreendimentos. Isso nos três casos investigados. Em relação ao capital social de ligação (Coleman, 1988), em particular, é possível visualizar, por exemplo, como as redes parcialmente densas dos empreendedores forneceram-lhes recursos considerados fundamentais. Três deles, enfatizados por Coleman $(1988,1990)$, foram aqui identificados: confiança, auxilio mútuo e recursos de maneira facilitada. O primeiro pode ser visualizado, por exemplo, quando Carlos Carvalho, empreendedor das Pimentas Lucha Libre, pediu apoio da esposa à abertura de sua empresa. "Do dia para a noite eu falei vamos fazer molho, conversei com a minha esposa, ela disse que me ajudaria, ela sempre me ajuda nas loucuras de encarar desafios"; ou ainda quando Bruno Vilela, empreendedor da Afro Brasil Turismo contou com o apoio de amigos. "Nessa época, [eles] eram os meus braços e pernas, me ajudou [sic] muito".

O "Auxílio Mutuo" pode ser visualizado, por exemplo, nos casos \#2 e \#3. Bruno exemplifica. "Eu tive a ideia de fazer um evento temático de Consciência Negra. Os meus vizinhos João e Pedro me ajudou [sic] na montagem". Ou quando Aline Amaral, empreendedora da Hortelar, contou com o apoio do marido no desenvolvimento de diferentes atividades. "O marido ajudava muito, tanto nos serviços braçais, quanto no desenvolvimento do site da Hortelar". Já os "Recursos de Maneira Facilitada", reflexo de suas densas redes sociais, foram obtidos pelos empreendedores \#1, \#2 e \#3. Os insumos necessários à produção inicial de Carlos, por exemplo, fora inicialmente dados por sua mãe. Salienta o empreendedor como ela havia plantando "muita pimenta, e não consegui[ria] vender tudo". Já Aline encontrou na sogra a oportunidade para divulgar seu trabalho. Isso porque, afirma, ela "trabalha em escola. Fez um convite para a Hortelar participar como empresa colaboradora". Segundo a empreendedora, "foi uma porta que se abriu que nos ajudou a divulgar o nosso trabalho". Já Bruno Vilela obteve do pai de um amigo o apoio necessário à abertura de sua empresa. "Na época", salientou o empreendedor, "não sabia como abrir a MEI e o João pediu para o pai dele abrir para mim, pois trabalhava num escritório de contabilidade, e nem me cobrou o serviço".

Em relação ao capital social derivado da intermediação (Burt, 2009), evidências de campo sugerem a importância da intermediação de contatos imersos em diferentes estruturas sociais aos empreendedores; como os contatos distantes forneceram-lhes recursos também considerados fundamentais. Ao Carlos por permitir vender mais. Ele conta como um contato distante obtido em uma feira o ajudou a iniciar nos negócios. "Fui conversar com um representante comercial e apresentei o meu produto [...]. Na semana seguinte", salientou o empreendedor, "ele havia me enviado um pedido de $\mathrm{R} \$ 2.500,00$, e eu falei, nossa! Não acredito!". Ao Bruno e à Aline por permitirem-lhes contatar pessoas inacessíveis de outra maneira. "No início, um vizinho indicava pro outro, um amigo de amigo comentava, e os 
ingressos eram todos vendidos", salientou Bruno. Já Aline enfatizou como um cliente distante comprou "o caixote e nos abriu a porta para fazermos um evento em seu condomínio".

No entanto, dados empíricos parecem projetar luzes para a manifestação de constatação adicional. A de que o capital social (fechamento e buracos estruturais) online, expresso nos recursos que os empreendedores obtêm através das mídias sociais, contribuem para a trajetória de desenvolvimento dos empreendimentos iniciais. Em relação ao fechamento, através de dois recursos específicos das redes digitais: persistência (\#2) e interoperabilidade (\#1 e \#3). Salienta Aline, por exemplo, como "as redes sociais meio que virou um banco de dados". Segundo a empreendedora, "quando estamos em um cliente, é lá [nas mídias] que buscamos informações de trabalhos realizados para mostrar para ele, é a prova que somos profissionais e comprovamos o que fazemos". Note como a possibilidade de ver informações arquivadas, associada no ambiente digital à "persistência" (Smith, Smith, \& Shaw, 2017), permite à empreendedora endossar as relações com os consumidores nos contextos online e também offline. "O benefício da rede social que o contato físico não permite vejo como o contato inicial, [...] mas para fechar, é preciso um contato mais direto, que pode ser pessoalmente", complementa. Já a interoperabilidade, isto é, a possibilidade de compartilhar conteúdos através de múltiplas e distintas plataformas digitais, demonstrou-se um recurso empregado na atuação de \#1 e \#3. Ambos o apropriava para divulgar seus produtos e atrair diferentes consumidores. "Após a montagem dos produtos na barraca", salienta Carlos, "tirávamos fotos e já postávamos no Instagram, Facebook e Stories do WhatsApp, assim todos podiam acompanhar onde estávamos e ir nos visitar". Note, aí, de maneira recursiva, a importância destacada do ambiente digital, também, para o contexto presencial. O empreendedor apropriava das mídias não apenas para reforçar as interações online com os contatos, como para atraí-los para oportunidades de interações no ambiente offline. Mais ainda, o empreendedor aproveitava os contatos presenciais para estimular, no ambiente digital, a proximidade relacional. Segundo ele, "muita gente usa o WhatsApp. Eu pedia o contato dos clientes para divulgar em qual feira estaríamos na semana seguinte, tanto por mensagem quanto pelo stories do aplicativo". Já para Bruno, "fazer Stories tanto no Face como no WhatsApp dá super certo porque eu já recebo no próprio aplicativo as mensagens de interesse de participar".

Quando relacionado aos recursos derivados da intermediação entre pessoas distanciadas entre si, os empreendedores parecem capazes de, no ambiente digital, empregar diferentes atributos relacionados às mídias sociais, corroborando literatura da área. Oito deles podem ser destacados. São eles: sinalização, replicabilidade, assincronia, pesquisabilidade, recuperabilidade, interatividade social, visibilidade e transversabilidade. $\mathrm{O}$ primeiro quando Carlos (\#1) salienta como "ao realizar um post de produtos da Lucha Livre, [ele] sempre deix[a] o post desbloqueado para [que] quem [veja] possa curtir e compartilhar em suas páginas"; como o perfil e as postagens das mensagens acabam atraindo novas pessoas, elevando a taxa de conexões com indivíduos interessados em seus produtos. Segundo o empreendedor, "quando as páginas das redes sociais são movimentadas, ela é recomendada para pessoas que tem interesse semelhante ao que está sendo divulgado, por isso atrai novos clientes". Note como tal iniciava acaba "comunicando informações intencionais e não intencionais sobre os empreendedores e seus empreendimentos" (Smith, Smith, \& Shaw, 2017, p. 25). A replicabilidade, por sua vez, pode ser observada na atuação da Aline (\#2). Ela argumenta como o "bom da divulgação das redes sociais é que [ela] permite a interação, modificação e replicação 
do conteúdo ao longo do tempo". Em suas palavras, "às vezes eu vejo uma postagem antiga, como o trabalho de horta da escola, e republico, atraindo novas escolas interessadas".

A assincronia, expressa na possibilidade de ultrapassar limitações temporais, extraindo dos laços conteúdos de interesse, pode ser visualizada como recurso apropriado por \#1 e \#2. "Toda venda que inicia através das suas redes sociais" é posteriormente finalizada pelo "WhatsApp", salienta Carlos. Aline, por sua vez, enfatiza como a divulgação nas mídias sociais das palestras ministradas em diferentes escolas acabou por permitir novos contratos à empresa. Segundo ela, "a gente começou a ter cliente em [novas] escolas devido a este trabalho". Outro recurso, pesquisabilidade, parece ser objeto de atenção do Bruno (\#3). Ele enfatiza como o Facebook o ajudou no desenvolvimento inicial de sua empresa. Com ele, defende, "pude pesquisar outras empresas que tinha a mesma ideia que a minha, e pude ver o que oferecia e como trabalhava". A recuperabilidade, manifesta na habilidade de vascular as redes para capturar informações específicas, foi utilizada pela Aline para analisar comportamentos de um concorrente em particular, diferenciando-a da oferta disponível. Segundo ela, o concorrente "não dava o serviço de troca de plantas. [...] Eu o seguia no Instagram". Já a "interatividade social", isto é, a possibilidade de compartilhar conteúdos através de múltiplas e distintas plataformas digitais, é um benefício do ambiente digital, segundo Bruno. Para ele, estar nas diferentes "mídias ajuda bastante, pois é uma maneira de divulgar o trabalho". A "visibilidade", compreendida como a habilidade de tornar as conexões de redes visíveis, parece também um atributo fundamental deste empreendedor. Ele salienta como não consegue ver "o [...] negócio sem essas ferramentas" digitais. Em suas palavras, "elas me trazem muitas pessoas que pessoalmente jamais conheceria".

Alguns recursos associados ao contexto digital e relacionados ao fechamento (compartilhamento, sinalização, visibilidade, editabilidade, revisibilidade, assincronia, interatividade social e escalabilidade) e aos buracos estruturais (escalabilidade, interoperabilidade, associação e transversabilidade) não foram, à despeito de sua ênfase na literatura, aqui identificados. Outro, o "Compartilhamento", por sua vez, demonstrou-se associado a um tipo de capital social ainda não identificado por estudos anteriores. Até então considerado recurso relacionado, no ambiente digital, exclusivamente aos benefícios derivados do fechamento, ele foi, aqui, identificado como que advindo da intermediação entre pessoas desconexas entre si. Isso na atuação da Aline. "Todo trabalho que realizamos tiramos fotos, e isso nos permite divulgar constantemente o nosso trabalho". Segundo ela, "foi assim com as hortas escolares. Começamos a receber convites pelo Instagram para fazer esses trabalhos em outras escolas". Note como a facilidade em compartilhar nas mídias sociais os trabalhos da empreendedora permitiu-lhe conectar, no ambiente digital, pessoas de outra maneira desconexas entre si. O quadro 2, a seguir, resume as evidências empíricas encontradas, associando-as aos construtos teóricos subjacentes.

Quadro 2: categorias teóricas de interesse, e sua relação com evidências de campo.

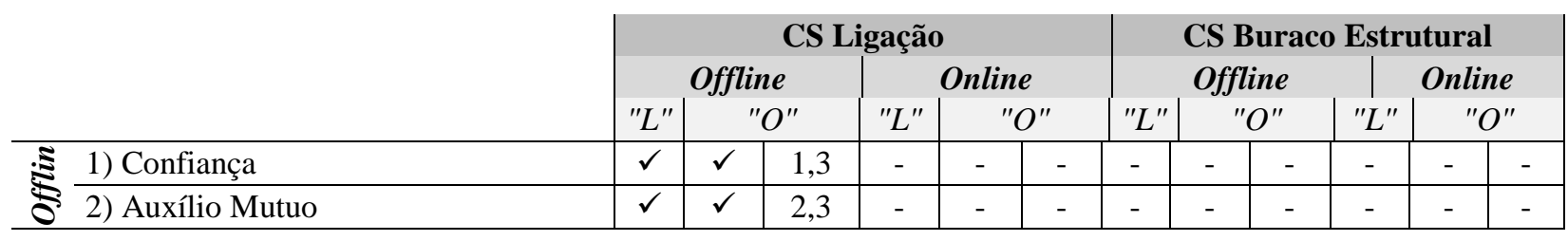




\begin{tabular}{|c|c|c|c|c|c|c|c|c|c|c|c|c|c|}
\hline & 3) Recursos de Maneira Facilitada & $\checkmark$ & $\checkmark$ & $1,2,3$ & - & - & - & - & - & - & - & - & - \\
\hline & $\begin{array}{lll}\text { 4) Acesso } & \text { a } & \text { novas } \\
\text { informações/recursos } & & \\
\end{array}$ & & & & & & & $\checkmark$ & $\checkmark$ & 1,3 & & & \\
\hline & 5) Perfis de usuários digitais & & & & & & & & & & & & \\
\hline & Compartilhamento & - & - & - & $\checkmark$ & $\mathbf{x}$ & - & - & - & - & $\mathbf{x}$ & $\checkmark$ & 2 \\
\hline & Sinalização & - & - & - & $\checkmark$ & $\mathbf{x}$ & - & - & - & - & $\checkmark$ & $\checkmark$ & 1 \\
\hline & Visibilidade & - & - & - & $\checkmark$ & 国 & - & - & - & - & - & - & - \\
\hline & Editabilidade & - & - & - & $\checkmark$ & $\mathbf{x}$ & - & - & - & - & - & - & - \\
\hline & Replicabilidade & & & & & & & & & & & & 2 \\
\hline & 6) Pesquisa Digital & & & & & & & & & & & & \\
\hline & Persistência & - & - & - & $\checkmark$ & $\checkmark$ & 2 & - & - & - & & & \\
\hline & Revisibilidade & - & - & - & $\checkmark$ & $\mathbf{x}$ & - & - & - & - & - & - & - \\
\hline$=$ & Assincronia & - & - & - & $\checkmark$ & $\mathbf{x}$ & - & - & - & - & $\checkmark$ & $\checkmark$ & 1,2 \\
\hline$\frac{2}{8}$ & Pesquisabilidade & - & - & - & - & - & - & - & - & - & $\checkmark$ & $\checkmark$ & 3 \\
\hline & Recuperabilidade & - & - & - & - & - & - & - & - & - & $\checkmark$ & $\checkmark$ & 2 \\
\hline & 7) Relações Digitais & & & & & & & & & & & & \\
\hline & Interatividade Social & - & - & - & $\checkmark$ & $\mathbf{x}$ & - & - & - & - & $\checkmark$ & $\checkmark$ & 3 \\
\hline & Escalabilidade & - & - & - & $\checkmark$ & $\mathbf{x}$ & - & - & - & - & $\checkmark$ & $\mathbf{x}$ & - \\
\hline & Interoperabilidade & - & - & - & $\checkmark$ & $\checkmark$ & 1,3 & - & - & - & $\checkmark$ & $\mathbf{x}$ & - \\
\hline & 8) Transparência de Rede & & & & & & & & & & & & \\
\hline & Visibilidade & - & - & - & $\checkmark$ & $\mathbf{x}$ & - & - & - & - & $\checkmark$ & $\checkmark$ & 3 \\
\hline & Associação & - & - & - & - & - & - & - & - & - & $\checkmark$ & $\mathbf{x}$ & - \\
\hline & Transversabilidade & - & - & - & - & - & - & - & - & - & $\checkmark$ & $\mathbf{x}$ & - \\
\hline
\end{tabular}

Legenda: "L" = literatura; "O" = Observado.

Fonte: elaborado pelos autores

\section{$5 \quad$ Considerações Finais}

Este artigo, resultado de pesquisa teórico-empírica, buscou investigar se e como os capitais sociais offline e online influenciam os empreendedores, analisando os recursos derivados e a dinâmica entre eles. Fez-se isto por meio do estudo qualitativo de três empreendedores de pequeno porte e em "Estágio Inicial", isto é, com até 42 meses de existência (GEM, 2018). Evidências de campo sugerem a constatação de importantes conclusões de pesquisa. A primeira de que ambas as dimensões do capital social offline (fechamento e buracos estruturais), aqui expresso nos recursos obtiveis através das interações presenciais, demonstrase importante à trajetória de busca pelo desenvolvimento dos empreendedores. O mesmo ocorreria com os benefícios advindos do capital social online. Com efeito, tal foi o identificado neste estudo. Dados empíricos sugerem a conclusão de que a busca pelo desenvolvimento dos empreendimentos iniciais parece ocorrer devido à combinação positiva de recursos advindos dos ambientes offline e online. Isto é, da habilidade dos empreendedores em obterem diferentes atributos de suas redes presenciais e digitais. Neste sentido, a trajetória de desenvolvimento de empreendimentos iniciais deverá ser teoricamente mais bem-sucedida na medida em que mais recursos os empreendedores conseguirem usufruir de ambas as esferas sociais.

Embora ambos os capitais sociais (offline e online) contribuam à busca pelo desenvolvimento de empreendedores iniciais, evidências de campo projetam luzes para a manifestação de constatação complementar: a de que eles aparentam desempenhar 
contribuições relativamente distintas entre si. Enquanto a dimensão offline demonstrou-se mais relevante no fornecimento de recursos derivados das redes densas, expressas nos diferentes auxílios obtidos pelos empreendedores com seus familiares e amigos mais próximos, a vertente online do capital social, por sua vez, aparentou-se mais relevante no fornecimento de recursos advindos da intermediação, isto é, da conexão entre pessoas distantes e/ou inacessíveis sob outra forma. Isso não é para dizer que a conexão de buracos estruturais no ambiente offline e/ou o fechamento das redes no contexto online não forneçam contribuições, apenas que elas se evidenciaram proporcionalmente menos evidentes em relação às dimensões análogas aqui investigadas. Tal fica ainda mais claro na análise do Quadro 2. Nele é possível observar, por exemplo, como, diversamente ao fechamento das redes, quando relacionado à conexão de pessoas distantes entre si, os empreendedores apropriam-se de diferentes atributos relacionados às mídias sociais. Tal conclusão sugere a relevância recursiva de ambas as esferas do capital social, e projeta luzes, de maneira inovadora nos estudos da área, para a natureza complementar entre elas.

No entanto, há algo além, projetando luzes, ainda, para a existência de outra constatação de considerável relevância teórica. Dados de campo sugerem a noção de que capital social online exerce influência sobre sua dimensão offline, e vice-versa. Tal foi o identificado neste estudo. Salienta Aline, por exemplo, como as mídias se tornaram uma espécie de banco de dados. Quando ela está presencialmente com um cliente, é lá que a empreendedora busca "informações de trabalhos realizados". Note como recursos disponíveis no ambiente digital (persistência) acabaram por permitir à empreendedora reforçar relações com os consumidores no contexto offline; como o ambiente "on" influenciou as interações "off". O mesmo ocorreu com Carlos. Segundo ele, "após a montagem dos produtos na barraca, tirávamos fotos e já postávamos no Instagram, Facebook e Stories do WhatsApp". Para o empreendedor, as postagens no ambiente digital permitiam aos consumidores acompanharem onde eles estavam, possibilitando-os visitarem. Observe como Carlos apropriava das mídias não apenas para reforçar as interações online com os contatos, como para atraí-los para oportunidades de contato no ambiente offline. Mais que isso, enfatiza Carlos como grande parte destas interações com os clientes no ambiente digital foi inicialmente obtida através de relações presenciais. Isso porque, sempre que encontrava novo consumidor nas feiras, reflexo da importância do buraco estrutural no ambiente offline, ele "pedia o contato dos clientes para divulgar em qual feira [estaria] na semana seguinte". Neste sentido, veja como os relacionamentos físicos permitiram interações no contexto online, e, de maneira análoga, como os contatos online possibilitaram e impulsionaram, por sua vez, interações no contexto offline. Há, neste sentido, evidências de relativa recursividade entre recursos e benefícios derivados de ambas as esferas sociais.

Novos estudos, teóricos e empíricos, devem avançar nas reflexões aqui apenas delineadas. Neste sentido, poderiam testar a contribuição do "compartilhamento" enquanto recurso advindo da intermediação nas mídias sociais, aqui identificado de maneira inovadora. Ao mesmo tempo, poderiam avançar nas limitações aqui identificadas, debelando-as. Inseremse: coletas de evidências restritas aos empreendedores e às contribuições das entrevistas semiestruturadas; ausência de dados comprovativos do desempenho empreendedor, entre outros. Sugestões de novos estudos incluem: comparações entre capital social offline e online entre empreendedores iniciais e nascentes, averiguando, sob perspectiva longitudinal, diferenciações entre recursos advindos de ambas as esferas; analisar a influência do capital 
social online ao desempenho organizacional de diferentes tipos de empreendedores, etc.. Esses e outros questionamentos permanecem aberto. Há ainda oportunidades para importantes descobertas.

\section{Referências}

Afandi, E., Kermani, M., \& Mammadov, F. (2017). Social capital and entrepreneurial process. International Entrepreneurship and Management Journal, 13(3), 685-716.

Ahmad, M., \& Khan, R. E. A. (2019). Does demographic transition with human capital dynamics matter for economic growth? A dynamic panel data approach to GMM. Social Indicators Research, 142(2), 753-772.

Bastié, F., Cussy, P., \& Le Nadant, A. L. (2016). Network or Independent Business? Entrepreneurs' Human, Social and Financial Capital as Determinants of Mode of Entry. Managerial and Decision Economics, 37(3), 167-181.

Birendra, K. C.; Morais, D., Seekamp, E., Smith, J., \& Peterson, M. (2018). Bonding and bridging forms of social capital in wildlife tourism microentrepreneurship: An application of social network analysis. Sustainability, 10(2), 315.

Boyd, D. M., \& Ellison, N. B. (2007). Social network sites: Definition, history, and scholarship. Journal of computer-mediated Communication, 13(1), 210-230.

Bucholtz, I. (2019). Bridging bonds: Latvian migrants' interpersonal ties on social networking sites. Media, Culture \& Society, 41(1), 104-119.

Burt, R. S. (2000a). Structural holes versus network closure as social capital. In N. Lin, K. Cook, \& R. S. Burt (Eds.), Social capital: theory and Research (pp. 31-56). Sociology and Economics: Controversy and Integration series

Burt, R. S. (2004). Structural Holes and Good Ideas. American Journal of Sociology, 110(2), 349-399. Retrieved from http://www.jstor.org/stable/10.1086/421787.

Burt, R. S. (2009). The Network Entrepreneur. In R. Swedberg (Ed.), Entrepreneurship: the social science view (pp. 281-307). Oxford University Press: New York

Coleman, J. S. (1988). Social Capital in the Creation of Human Capital. The American Journal of Sociology, 94, 95-120.

Coleman, J. S. (1990). Social Capital (pp. 300-321). The Belknap Press of Harvard University Press: Cambridge

Donath, J. (2007). Signals in social supernets. Journal of Computer-Mediated Communication, 13(1), 231-251.

Eisenhardt, K. M., Graebner, M. E., \& Sonenshein, S. (2016). Grand challenges and inductive methods: Rigor without rigor mortis. Academy of Management Journal, 59(4), 11131123.

Fosić, I., Kristić, J., \& Trusić, A. (2017). Motivational Factors: Drivers Behind Women Entrepreneurs' Decision to Start an Entrepreneurial Venture in Croatia. Scientific Annals of Economics and Business, 64(3), 339-357.

Fukugawa, N. (2018). The contingent effect of social capital on performance of professional athletes: life cycle stages and changes in regulation as moderators. Applied Economics, 50(15), 1676-1693. 
Gaskell, G. (2002). Entrevistas individuais e grupais. In M. Bauer, \& G. Gaskell (Eds.), Pesquisa Qualitativa com Texto, Imagem e Som: um manual prático (pp. 64-83). Petrópolis: Vozes

Gayen, K., Raeside, R., \& McQuaid, R. (2019). Social networks, accessed and mobilised social capital and the employment status of older workers: A case study. International Journal of Sociology and Social Policy, 39(5/6), 356-375.

Giudici, G., Guerini, M., \& Rossi-Lamastra, C. (2018). Reward-based crowdfunding of entrepreneurial projects: the effect of local altruism and localized social capital on proponents' success. Small Business Economics, 50(2), 307-324.

Granovetter, M. (1973). The strength of weak ties. American Journal of Sociology, 78(6), $1360-1380$.

Han, J. (2018). Team-bonding and team-bridging social capital: conceptualization and implications. Team Performance Management: An International Journal, 24(1/2), 17-42.

Hernández-Carrión, C., Camarero-Izquierdo, C., \& Gutiérrez-Cillán, J. (2017). Entrepreneurs' social capital and the economic performance of small businesses: The moderating role of competitive intensity and entrepreneurs' experience. Strategic Entrepreneurship Journal, 11(1), 61-89.

Hmieleski, K. M., Carr, J. C., \& Baron, R. A. (2015). Integrating discovery and creation perspectives of entrepreneurial action: The relative roles of founding CEO human capital, social capital, and psychological capital in contexts of risk versus uncertainty. Strategic Entrepreneurship Journal, 9(4), 289-312.

Hoang, H., \& Antoncic, B. (2003). Network-based research in entrepreneurship: a critical review. Journal of Business Venturing, 18, 165-187.

Kaasa, A. (2009). Effects of different dimensions of social capital on innovative activity: Evidence from Europe at the regional level. Technovation, 29(3), 218-233.

Kane, G. C., Alavi, M., Labianca, J., \& Borgatti, S. (2014). Integrating social networks and information systems: A review and framework for research. MIS Quarterly, 38(1), 275304.

Kaplan, A. M., \& Haenlein, M. (2010). Users of the world, unite! The challenges and opportunities of Social Media. Business horizons, 53(1), 59-68.

Kim, B. Y., \& Kang, Y. (2014). Social capital and entrepreneurial activity: A pseudopanel approach. Journal of Economic Behavior \& Organization, 97, 47-60.

Luu, T. (2017). Ambidextrous leadership, entrepreneurial orientation, and operational performance: Organizational social capital as a moderator. Leadership \& Organization Development Journal, 38(2), 229-253.

Mahmood, Q. K., Zakar, R., \& Zakar, M. Z. (2018). Role of Facebook use in predicting bridging and bonding social capital of Pakistani university students. Journal of Human Behavior in the Social Environment, 28(7), 856-873.

Monitor, G. E. (2018). Global Report 2017/18. Global Entrepreneurship Research Association (GERA): London, UK.

Nahapiet, J., \& Ghoshal, S. (1998). Social capital, intellectual capital, and the organizational advantage. Academy of management review, 23(2), 242-266.

Naseri, S. (2017). Online social network sites and social capital: a case of facebook. International journal of applied sociology, 7(1). 
Neira, I., Calvo, N., Fernández, L., \& Portela, M. (2017). Entrepreneur: do social capital and culture matter?. International Entrepreneurship and Management Journal, 13(2), 665-683.

Paiva Júnior, F. G., Souza Leão, A. L. M., \& de Mello, S. C. B. (2011). Validade e confiabilidade na pesquisa qualitativa em administração. Revista de Ciências da Administração, 13(31), 190-209.

Pedrini, M., Bramanti, V., \& Cannatelli, B. (2016). The impact of national culture and social capital on corporate social responsibility attitude among immigrants entrepreneurs. Journal of Management \& Governance, 20(4), 759-787.

Ryu, S. (2017). To bond or to bridge? Contingent effects of managers' social capital on organizational performance. The American Review of Public Administration, 47(4), 403-418.

Smith, C., Smith, J. B., \& Shaw, E. (2017). Embracing digital networks: Entrepreneurs' social capital online. Journal of Business Venturing, 32(1), 18-34.

Stam, W., Arzlanian, S., \& Elfring, T. (2014). Social capital of entrepreneurs and small firm performance: A meta-analysis of contextual and methodological moderators. Journal of business venturing, 29(1), 152-173.

Vixathep, S. (2017). Entrepreneurship, human and social capital, and government policy in small and medium enterprise development in Laos. Japan Social Innovation Journal, 7(1), 33-50.

Wahid, F., \& Indarti, N. (2013). Facebook, online social capital, and the rise of nascent entrepreneurs. Innovation, Communication and Engineering, 61.

Williams, D. (2006). On and off the'Net: Scales for social capital in an online era. Journal of computer-mediated communication, 11(2), 593-628.

Williams, N., Huggins, R., \& Thompson, P. (2017). Social capital and entrepreneurship: does the relationship hold in deprived urban neighbourhoods?. Growth and Change, 48(4), 719743.

Yin, R. K. (2015). Estudo de Caso: planejamento e métodos. Porto Alegre: Bookman 